\title{
Planning for future provision of dental services in prison: an international proposal of two systems
}

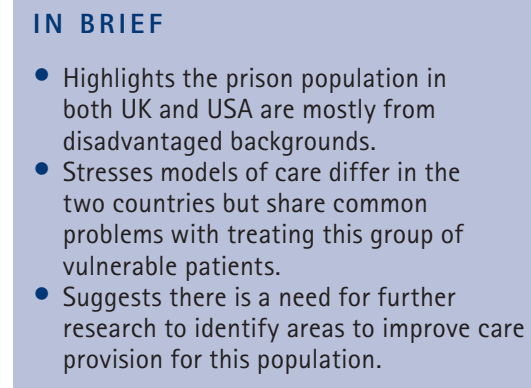

\section{VERIFIABLE CPD PAPER}

This article describes a proposal for the future organisation of the delivery of dental and oral health services for prisoners. This vision is based on an analysis of the existing prison dental programmes in England and the United States (Federal Bureau of Prisons, [FBOP]), together with discussions from two key individuals from both countries who championed changes to prison dental services and have published in the field of prison dental services. Both countries have similar visions. Some of the suggested work has already been addressed in the past (for example, introduction of state of the art dental facilities in the UK prison setting), some are in process (for example, electronic patients' records) and some may be addressed in the near future (for example, prisoners' involvement with the services provided for them). Some of the expressed visions for the future in this article are driven by evidence-based literature and dental workforce policy.

\section{INTRODUCTION}

The prison population is increasing. There were more than 83,637 prisoners in the UK in 2013. ${ }^{1}$ Although the number of older prisoners (50+) has increased by $10 \%$ between 2010 and 2011, the prison population is still a young population with 78\% of the population between the ages of 22 to $49 .^{2}$ Male prisoners are less likely than the general population to use preventive health services (such as screening, immunisation and health advice) pre-imprisonment. Both male and female prisoners are more likely to practise health-damaging behaviours involving smoking, poor diet and recreational drug and alcohol use. ${ }^{2}$ Moreover, this particular group is more likely to commit crime as a consequence of substance use or mental ill-health. In addition to higher levels of poor general health, they have high levels of unmet normative and perceived oral health needs. This can put pressure on prison healthcare

Senior Specialist Clinical Teacher, ${ }^{4}$ Consultant in Special Care Dentistry, ${ }^{5}$ Professor of Psychology as Applied to Dentistry, King's College London Dental Institute, Floor 26, Tower Wing. Guy's Hospital, Great Maze Pond, London, SE1 9RT; ${ }^{2}$ Head, International Centre for Child Oral Health Director, Global Child Dental Health Taskforce, Wellington House, 133-155 Waterloo Road, London,

SE1 8UG; ${ }^{3}$ Chief Dentist for Federal Bureau of Prisons, Washington, United States

${ }^{*}$ Correspondence to: Dr Ellie Heidari

E-mail: ellie.heidari@kcl.ac.uk

\section{Refereed Paper}

Accepted 25 April 2014

DOI: 10.1038/sj.bdj.2014.704

${ }^{\circledR}$ British Dental Journal 2014; 217: 177-182 services. However, high levels of oral/dental treatment need can produce opportunities when/if funding becomes available, to integrate oral health into general healthcare promotion and treatment systems.

In the UK, prison dental services are generally demand-based and currently some establishments are failing to meet prisoners' dental health needs due to long waiting lists for treatment. This depends on how dental services are commissioned (contracted hours and agreed types of treatment) and the normative dental need within the local unit. Because of limited resources within secure settings and prisoners' high level of oral disease, many prison dentists prioritise provision of emergency care rather than routine care. This is especially true when there is a high turnover of prisoners and limitations in the commissioned treatment service provision.

Additionally, prison populations are mobile, which can lead to discontinuation of care and incomplete dental treatments. The unpredictable nature of prison life can also make the delivery of services difficult. Therefore, the current overall aim of the provision of prison dentistry in the UK, although not ideal, is to assess and treat the urgent needs of prisoners and also to get sentenced prisoners dentally fit before their release.

A closer look at this population in England and Wales reveals that many who are imprisoned are poor, have mental health problems, or come from disadvantaged backgrounds. ${ }^{3-6}$
In general, prisoners have poor health, with main issues being mental health, substance abuse and communicable disease. ${ }^{3-5}$ In the USA, reconciling correctional healthcare costs has always been challenging. According to Delgado, ${ }^{7}$ it is difficult to separate society's values as it relates to crime and punishment. Therefore, justifying costs may not within the grasp of 'ordinary' citizens, elected officials, and policy makers. ${ }^{7}$

Prison may be the first time that prisoners are provided with healthcare on a regular and ongoing basis. This is particularly true for prisoners in the US ${ }^{7,8}$ as healthcare is less freely available than in the UK. Yet despite the inherent differences in the healthcare systems across the two countries, it is clear that the oral health needs of both countries' prisoners are high. In the UK, this is highlighted in the Department of Health's, and Her Majesty Prison Service's publication Strategy for modernising dental services for prisoners in England, which was published in April 2003. ${ }^{9}$ Another report also suggested a need for increased dental service provision to cope with the increase in the prison population. ${ }^{10}$ The ability to provide care for this population presents unique challenges requiring a specialised work force in both countries, developed through strong leadership.

Professor Bedi was Chief Dental Officer for England (2002 to 2005) and led the prison dental service reforms in England. During his 3 years in post he implemented significant 
change programmes in NHS dentistry, in particular research into oral health and secure provision through $£ 4$ million pounds in funding.

Dr Makrides is a Commissioned Officer in the United States Public Health Service and was assigned to the Federal Bureau of Prisons (FBOP) as a staff dentist in 1987. Over the past 26 years, Dr Makrides has worked in various clinical and administrative assignments. In 2001, he was appointed the FBOP's Chief Dentist in Washington DC. He is a specialist in dental public health and has postgraduate degrees in public health and healthcare management. In addition to his post as the Chief Dentist, he is a correctional dentistry consultant to the American Dental Association and serves on the Board of Directors of the National Commission on Correctional Health Care.

The purpose of this article is to examine visions of modern prison dental services by looking at the two countries' prison dental systems and their past and possible future, based on the dental leaders' opinions and the available literature.

\section{HEALTHCARE PROVISION IN HER MAJESTY'S PRISON SERVICES}

In England, healthcare provision in prisons has historically been organised by Her Majesty's Prison Service (HMPS) that reported to the Home Office, a department of central government. In 2002, the Secretary of State for Health decided that the funding responsibility for prison healthcare should transfer from the Home Office to the Department of Health (DH). In addition, the government announced that from April 2006 local health commissioners called Primary Care Trusts (PCTs) would take responsibility for the commissioning of prison health services rather than the Home Office. This reorganisation was based on the HM Inspectorate of Prisons' discussion paper Patient or prisoner? A new strategy for healthcare in prisons. ${ }^{11}$ This report highlighted the disparity in the quality and range of healthcare services provided by different prison establishments. It formed the basis for the recommendation to move healthcare provision to the National Health Service (NHS) and was considered by a joint committee made up of the Prison Service and the NHS Executive. However, with a change of UK government in 2009, it was suggested that the commissioning of the services might be transferred to primarily commissioning groups led by a primary care service provider. $^{12}$

In 2012, the government decided to transfer responsibilities for commissioning health for secure children's homes in England from youth justice to the NHS. However, young offender institutions (YOIs) are run partly by the National Offender Management Service (NOMS). ${ }^{2,13}$ From April 2013, the commissioning for prisons' healthcare services (including dentistry) and facilities became the responsibility of NHS England, which is an independent NHS commissioning board. ${ }^{14}$ The National Offender Management Service and NHS England, with support of Public Health England (PHE), are planning to work in partnership to co-commission and deliver health services. ${ }^{14}$

\section{PRISON DENTAL SERVICES IN ENGLAND}

The DH published its paper entitled Strategy for modernising dental services for prisoners in England in April 2003. ${ }^{9}$ It estimated that the level of untreated dental disease among prisoners was four times greater than that of the general population from similar social backgrounds. It also demonstrated that prison dental services vary in quality, type and availability of treatment. The variation in the levels and quality of care before the publication was dependant on factors such as outdated prison establishments with inadequate facilities, and varied service level agreements (SLA), which could limit the care provided for prisoners. Service agreements often varied for each provider and the providers came from different backgrounds.

Providers could range from independent contractors, such as self-employed general dental practitioners (General Dental Service [GDS] contract) to employed salaried (community) dental service personnel with different experiences and training for provision of care for vulnerable people. The Strategy for modernising dental services for prisoners in England in April $2003^{9}$ attempted to create a more universal approach to service provision and suggested that the dental service should:

- Offer a universal service based on clinical need

- Provide an appropriate range of dental services

- Shape services around the needs of patients

- Be responsive to the needs of different prison populations

- Continually improve its services

- Support its staff

- Cooperate with others

- Work to reduce health inequalities

- Offer open access to information about services and treatments.

Later that year, in the UK, the DH and HM Prison Service announced a wish to establish a Prison Health Research Network (PHRN) to support all clinical aspects of healthcare related to imprisonment. In addition, the Chief
Dental Officer determined to review the prison dental health system and compliance with the published report. In 2003, he commissioned the Office for Public Management (OPM) to undertake the review. In $2005 \mathrm{DH}$ published their document Reforming the prison dental service in England - a guide to good practice, which reviewed the progress that had been achieved by prison dental services. ${ }^{10}$

This highlighted and provided evidence where possible in areas that were mentioned in the $2003 \mathrm{DH}^{9}$ document. It also showed the complex nature of prison dentistry provision. of value to oral healthcare professionals is the section on best practice recommendations in each of the five categories: health needs assessment; oral health promotion and health improvement; increasing access to treatment; continuity and follow up care; and using contracts and service specifications to improve service quality. As previously mentioned, service provision can vary dependent on the nature of the service level agreement. This, combined with the high normative prisoners' need and part time facilities/staff, can dramatically increase the time it takes for oral healthcare providers to address these needs.

The 'new' NHS dental contract by DH in April 2006, replaced both GDS (fee-for-service payment) and Personal Dental Services (PDS) (quasi salary). In the UK remuneration (payments) from the commissioners to the majority of service providers changed to payment per completed treatment (in four different bands, with one being a routine examination and four being dentistry requiring laboratory work). Depending on SLA the providers needed to carry out set amounts of 'units of dental activity' (UDAs) within each banded treatment. If the UDAs completed were higher or lower than the commissioning value (which was an estimation based on previous year's work) adjustments to contracted payments might occur.

The system did not consider variation in dentists' experience, preference, cost and time for provision of care within a prison environment. The House of Commons health committee in their report in 2007/08, ${ }^{15}$ highlighted that this system failed to improve dental services in terms of access and quality of care for patients and many prison dental providers had difficulty in achieving their UDA targets. The report made recommendations to improve the 2006 dental contract.

Additionally, any prison remuneration system also needed to take the 13 privately run prisons into consideration. ${ }^{16}$ Other issues to be considered in these prison establishments are safety for prisoners and staff, lack of inspection by relevant bodies and cost to run the establishments. ${ }^{17}$ In 2012, it was mentioned that commissioning for offenders 
must include access to comprehensive health services equal to the same standard as the public. ${ }^{2,13}$ This responsibility rested with the NHS Commissioning Board (NHS CB) in partnership with NOMS. NHS England (formally known as NHS Commissioning Board) will continue to commission care in all prisons and ensure that the provided care is consistent in terms of quality, safety, access and value for money. ${ }^{14}$

\section{PRISON DENTAL SERVICES IN THE US FEDERAL BUREAU OF PRISONS (FBOP)}

Unlike European nations that have one correctional system, the US, with more than 50 states. There could be a wide variety of state jurisdictions. The level of care provided within the jurisdictions is not standardised across the US.

Given the diversity of the systems, the authors have selected the FBOP, as the representative jurisdiction as there are many shared similarities. The FBOP is the largest correctional jurisdiction in the United States and comprises 119 prisons and more than 216,000 prisoners. Prisoners who are remanded to the custody of the FBOP have committed federal offences (for example, fraud, murder, manslaughter, etc).

The provision of healthcare is the responsibility of the Bureau's medical director. The oral health component is delegated to the chief dentist, who is responsible for policy development, quality assurance, and programme management. Further delegation is given to regional chief dentists who are assigned to the six regions of the FBOP. The FBOP employs over 150 full time dentists to provide oral healthcare to offenders. These providers are federal government employees who work as civil servants or as commissioned officers in the United States public service.

In the FBOP, healthcare policy is developed by the American Correctional Association (ACA) and Joint Commission Standards. These agencies provide the guidelines that serve as a matrix by which policy is developed. The FBOP strives to incorporate evidence-based practice into the development of policy to include guidance from other governmental agencies such as the Centres for Disease Control (CDC) and the Food and Drug Administration (FDA).

Dental care in the FBOP is triaged. Many prison establishments in the UK also have a triage system in place. Immediate needs (pain, swelling, infection) emergency/urgent care is given the highest priority. Access to this care in the FBOP is initiated by the prisoner. Prisoners may request routine care by submitting a request and being placed on an institutional waiting list. Accessory care (implants, fixed prosthetics, and orthodontics) is approved on a case by case basis by the regional chief dentists and the chief dentist of the FBOP.

\section{FINDINGS}

One of the United Nations' (1990) ${ }^{18}$ principles emphasises the rights of prisoners to have the same healthcare as everybody else in society. Based on that principle the prison health services should provide the same standard of health services available in the wider community. For implementation of this principle, there is a need to identify the general and oral health status of prisoners, by collecting data through epidemiological surveys. Identified normative needs can then be used to influence service development and be brought to the attention of the government, commissioners and other providers.

\section{FACILITIES}

\section{Electronic patient management systems}

Cornford et al. ${ }^{19}$ mentioned that only $9 \%$ of prisons said that prisoners' clinical information was entered directly onto a computer indicating that information technology (IT) use is poor. In 2012, it was mentioned that electronic information systems are now available in most prisons and healthcare should integrate with these systems. ${ }^{2}$ Electronic patient data systems can facilitate standardised data collection, and give instant access and overview of prisoners' general and oral health status. Such data is easily transferable between institutions if standardised software programmes are used. This will also have an implication on continuation of patients' care as communication between care providers within and outside prison establishments can be established. It is important that any electronic dental data system is user friendly. Unfortunately, some colleagues working in UK prison establishments find the current IT systems challenging.

In the US FBOP, an electronic medical record is widely used by all healthcare providers. It is anticipated that future development will provide electronic data sets that would integrate medical and dental records with research systems. Both leaders agree that the implementation of electronic records would additionally improve clinical audit ${ }^{20}$ and service evaluation. Therefore, the cost of well-maintained computer systems should be calculated into state of the art dental facilities.

\section{Dental facilities in prisons}

Oral healthcare providers should have modern, functional, safe and sanitary clinics to provide care. This serves two purposes. The first is to provide prisoners with improved access by having dedicated facilities for oral healthcare. The second purpose is to provide dental staff with reliable equipment and adequate supplies to provide high quality care. It is essential that a work environment is fit for purpose. The Department of Health ${ }^{9}$ found that many UK prison establishments lacked basic facilities and equipment such as $\mathrm{X}$-ray machines.

US FBOP clinics are standardised and are required to have equipment replacement plans. In 2012, all of the FBOP dental clinics had converted from cellulose-based films to digital radiography. New builds have ergonomic work space/plans to include ample space for sterilisation and storage. There is concurrence by both leaders that functional and modern equipment provides a less stressful environment for the clinicians.

\section{RESEARCH}

Collecting and analysing valuable data enables programme managers or commissioners to understand the population needs for appropriate funding allocation, guideline and policy development. However, conducting research in a prison setting can be difficult. The majority of healthcare providers within prison settings are clinical staff and not trained researchers. To incorporate research into clinical activity would require either researchers employed or research trained healthcare providers. Prisoners are considered a vulnerable group in terms of research governance, and therefore ethical approvals for research can take longer. This, together with confidentiality fears and restricted access to prisons to carry out research can make research difficult to achieve.

The need for research to be carried out in prison dentistry for evidence-based practise is obvious and specific prison focused evidence-based practise guidelines are lacking. Good research can help to address this. The World Health Organisation's report ${ }^{18}$ states that its "purpose of the publication of WHO Health in Prisons, was to highlight the similar public health issues that most of its Member States have and to share the developments in dealing with these issues'. There will be a new edition of the WHO report due in spring 2014.

In order to maintain a high standard of care a quality assurance system of policies and practises is needed. Electronically collected data can assist the assessment of current practices and needs of the prisoners. This view is consistent with the OPM's report Reforming prison dental services in England - a guide to good practice. ${ }^{10}$ This has been highlighted by the DH and PHE in order for prisons to collect 
evidence to support prison health outcome framework indicators (PHPQIs). ${ }^{20}$

\section{DENTAL WORKFORCE}

\section{Recruitment and retention of the dental workforce}

Several countries in Europe and the United States are experiencing difficulties in recruiting professional prison staff.

Issues affecting recruitment and retention of staff range are:

- Many dentists are retirement eligible (FBOP)

- Private sectors offer higher income

- Lack of prestige

- Limited training and career opportunities

- Higher stress levels dealing with a challenging patient group (people who have mental health problems and learning difficulties)

- Skill atrophy, there are very few opportunities to provide advanced treatments to patients. The primary goal is the provision of 'basic' dentistry

- In some prison establishments, poor integration with other health services in order to provide care and prevention programmes.

In the United States the recruitment and retention of staff has been improved by inducements such as training and monetary encouragements in the form of bonuses or higher salaries. The FBOP provides annual refresher training (ART) to all employees, on wide variety of topics that relate to correctional management and techniques.

Moreover, the FBOP recognises that working in a correctional environment can be stressful to staff and provides counselling and support services. An employee assistance programme is offered to all employees. This is particularly important as Rose and Cleary ${ }^{22}$ found that care staff, in contact with people with learning disabilities and a forensic history, were fearful of work-related violence due to patients' challenging behaviour. Some prison establishments in the UK offer training in recognition of early signs of violence and mental illness, in self-defence and crisis management. This may help employees to feel prepared and more confident. The ultimate responsibility for providing this should lie with the management.

Prison environments and prisoners challenge oral healthcare providers in many ways. Firstly, prisoners may demonstrate anti-social behaviours, ${ }^{7}$ which are not commonly seen in the wider community. This challenge requires training of prison dentists to deal with prisoners' behaviour. Prisons can also support its new staff with 'an effective induction programme', ${ }^{10}$ which includes all aspects of prison safety management, social and healthcare systems and emergency procedures.

The prison establishment might retain staff and increase quality service provision by involvement of staff in decision-making processes by encouraging interdisciplinary working. Staff retention, continuing education and training for prison dental staff can be influenced by the provision of high quality training.

\section{Training and career opportunities in prison dentistry}

Both respondents felt that recognition of a speciality worldwide where prison dentistry plays an important role would improve the quality of care and perhaps enhance its attractiveness to clinicians. Dentists should have "appropriate qualifications and work within a clinical quality assurance framework' ${ }^{23}$

In both the UK and the US, for many years there were no defined professional training pathways or a recognised speciality of prison dentistry. Although prison dentistry is provided by many dedicated general dental practitioners who have indepth individual knowledge and insight into prisoners' needs. There is no formal training pathway. A training pathway would allow formulation and development of generic and specific skills required for prison dentistry. Skills for prison dentistry were highlighted in the dentists with special interests (DwSIs) in prison dentistry document. ${ }^{23}$ In order for dentists to promote themselves as a DwSI in prison dentistry they should have knowledge of several areas specific for the provision of care for prisoners. Examples include legal and security issues around prisons, blood borne infections, mental illnesses, drug use and minor oral surgery. In England, support from commissioners to appoint or recognise DwSIs in prison dentistry has been limited.

In 2008, the UK General Dental Council (GDC) approved the speciality in special care dentistry (SCD), which can be considered as another training pathway. While most prison dentists are clinicians some would receive training in dental public health and participate in research and service commissioning.

According to the WHO report ${ }^{18}$ 'training in confidentiality, patient rights and human rights, epidemiology, of how diseases spread and of how lifestyle and socioeconomic backgrounds can influence ill health... potential threats to health and to detect early signs of mental health problems' is important. ${ }^{18}$ We would add training in patients with complex health needs and multidisciplinary working. Formal training can be supported by informal mentoring to provide adequate support for dentists wishing to pursue careers in prison dentistry.

In the UK, the National Association for Prison Dentistry (NAPDUK), which was established in 2007, organises a national study day annually. ${ }^{24}$ The organisation also offers support and information to members and government bodies when consulted. Recently, NAPDUK has been in discussions with PHE, NOMS and DH to improve dental health service provision by looking at the current situation. It conducted a nationwide survey in 2013 and surveyed oral health kits within prison establishments. Committee members in each of the four divisions (London, South, North, Midlands) also organise regional study days.

The reasons for recruitment difficulties are multi-factorial and not simply a training issue. It might relate to the complexity of the patient group, high level of normative needs, high turnover of prisoners (particularly in remand centres), ${ }^{25}$ limitations in provision of care, working in a prison environment, security issues, additional skills that are required from the dentist and dental team and in some cases long waiting lists.

\section{SPECIALISATION WITHIN THE PRISON DENTAL SERVICES}

Special care dentistry (SCD) in the UK has been described as "the improvement in oral health of individuals and groups in society, who have a physical, sensory, intellectual, mental, medical, emotional or social impairment or disability or, more often, a combination of a number of these factors. ${ }^{26}$ SCD caters for diverse client groups such as people living at home, in long stay residential care and secure units as well as homeless people. ${ }^{27}$ So it seems logical that prisoner groups should be included and come under the remit of SCD. SCD also provides services for people with a range of health conditions that may result in their oral health being compromised directly through the condition itself, indirectly through medications/treatment or simply because they find access to care difficult because of their impairment.

In the US, the FBOP conducts national meetings for dentists and their staff on a biennial basis. Internet meetings using broadband technology (CENTRA) are common. Besides acquiring postgraduate training in prison dentistry opportunities are available to train as part of the prison management team. FBOP clinical providers can opt for career paths specialising in correctional management or administration.

The authors believe that expanding the role of health care providers to allow movement to other career paths within prisons 
may help foster better working relationships with healthcare providers and custodial staff. It may also improve the oral health carer's negotiation and communication skills, which are essential for commissioning services and lead to great inter-professional working relationships.

Another important relationship to establish is with prisoners. Their engagement in prison healthcare service planning, community care upon release and rehabilitation would lead to a more targeted patient centred care delivery. Their input into care provision is valuable and a good relationship with healthcare staff might decrease the high level of complaints about the provided care and in some cases distrust in prison healthcare providers within a prison setting.

\section{CONCLUSION}

Dental healthcare provision in prisons will face a number of challenges. Solutions to these challenges can only take place with a full understanding of the complexity of the prison setting and care provision for its population by task holders in the system. In the UK, the majority of prison dentists are competent and experienced general dental practitioners or community dental officers. Prison oral healthcare providers often require additional special care knowledge, skills and training to meet the challenges present by oral healthcare provision in prisons. Skills in managing and commissioning dental services for vulnerable groups and also working in multidisciplinary teams are beneficial.

The competency framework ${ }^{23}$ is appropriate for prison dentists who want to work towards DWSI status, but there is a need to make commissioners of dental services aware of the skills required for prison dentists. As the prison population profile changes, demands on the prison dental service provision must adapt and follow.

The HMPS aim to offer an efficient, high quality service that meets prisoners' needs. Prison establishments should regularly monitor their services using appropriate measures of quality in agreement with local, national and international healthcare standards. This can be achieved if standardised assessment and care plans/protocol for some of the common prisoners' oral healthcare needs are established.

Prisoners' records should be readily available, ideally in electronic form that can be transferred between institutions, organisations and for community care providers as required. The service should have feedback and involvement of prisoners. ${ }^{28}$

Providers of services, the management team, and prison staff who are involved in a multidisciplinary clinical governance framework should all work together to identify where areas of need and service require improvement. Providers of the healthcare services should communicate regularly with commissioners. If the needs are based on evidence, both locally and nationally, then a commitment to research may allow investigation into innovative ways to improve services for both prisoners and staff.

Effective, targeted, professional development and specialist training courses can potentially improve retention of many devoted prison dentists. There is also a need for increased partnerships with academic training institutions. Either to train prison healthcare staff in research or for the institutions to offer researchers who can support programmes in prison research. Prison establishments should encourage research and researchers to enter their establishments.

Interprofessional health and social teams are very useful and necessary, especially as prisoners have complex medical, dental and social histories. Professional societies and networks (such as NAPDUK) can offer support to members, information about recent research and encourage prison oral healthcare providers to work towards best practise and evidence based guidelines.

Prison health is also a public health issue and its policy should be part and parcel of the broader general health services and an integral part of the national health policy of both countries. Gatherer et al. ${ }^{29}$ emphasised that a step forward can be taken by establishing a group of countries who are interested in improving healthcare for prisoners, where they can share their experiences and perhaps produce guidance based on best practices.

Opinions expressed in this article are those of the authors and do not necessarily represent the opinions of the Federal Bureau of Prisons or the Department of Justice or Department of Health.

Ellie Heidari would like to thank the members of the NAPDUK, especially executive committee members, for promoting the oral health of UK prisoners.

1. Ministry of Justice. Prison population bulletin. London: Ministry of Justice, 2013. Online information available on https://www.gov.uk/government/ publications/prison-population-figures (accessed June 2014).

2. Department of Health, NHS Commissioning Board. Public health functions to be exercised by the NHS Commissioning Board. Service specification No 29. Public health services for people in prison or other places of detention, including those held in the young people's secure estate. Online article available at https://www.gov.uk/government/uploads/system/ uploads/attachment_data/file/213171/29-Peoplein-prison-specification-121025.pdf (accessed June 2014). London: DH, 2012.

3. Rouxel P, Duijster D, Tsakos G, Watt R G. Oral health of female prisoners in HMP Holloway: implications for oral health promotion in UK prisons. Br Dent J 2013; 214: 627-632.
4. Singleton N, Meltzer H, Gateward R et al. Psychiatric morbidity among prisoners in England and Wales. London: The Stationery Office, 1998.

5. Watson R, Stimpson A, Hostick T. Prison health care: a review of the literature. Int J Nurs Stud 2004; 41: 119-128.

6. Heidari E, Dickinson C, Fiske J. An investigation into the oral health status of male prisoners in the UK. J Disability Oral Health 2008; 9: 3-12.

7. Delgado M, Humm-Delgado D. Health and healthcare in the nation's prisons: issues, challenges and policies. Maryland: Rowmann \& Littlefield Publishers, 2009.

8. Mixson J M, Eplee H C, Feil P H, Jones J J, Rico M. Oral health status of a federal prison population. J Public Health Dent 1990; 50: 257-261.

9. Department of Health. Strategy for modernising dental services for prisoners in England. London: DH, 2003.

10. Harvey $S$, Anderson B, Cantore S, King E, Mailk F. Reforming prison dental services in England: a guide to good practice. London: Department of Health, 2005

11. Home Office. Patient or prisoner? A new strategy for health care in prisons. London: Home Office, 1996.

12. Department of Health. Equity and excellence: liberating the NHS (white paper). London: DH, 2010. Online article available at https://www.gov. uk/government/uploads/system/uploads/attachment_data/file/213823/dh_117794.pdf (accessed June 2014).

13. NHS Commissioning Board. Securing excellence in commissioning for offender health. NHS Commissioning Board, 2013. Online article available at http://www.england.nhs.uk/wp-content/ uploads/2013/03/offender-commissioning.pdf (accessed June 2013).

14. NHS England, National Offender Management Service, Public Health England. National partnership agreement between: National Offender Management Service, NHS England and Public Health England for the co-commissioning and delivery of healthcare services in prisons in England. NHS England Publications, 2013.

15. House of Commons Health Committee Dental Services. Fifth report of session 2007-2008: Volume I and Volume III. London: House of Commons Health Committee, 2008. Online reports available at http://www.parliament.the-stationery-office. com/pa/cm200708/cmselect/cmhealth/289/289i. pdf and http://www.publications.parliament.uk/ pa/cm200708/cmselect/cmhealth/289/289iii.pdf (accessed June 2014).

16. Department of Justice. Contracted-out prisons. Online list available at https://www.justice.gov.uk/ about/hmps/contracted-out (accessed June 2014)

17. Criminal Justice Alliance. Delivering justice: the role of the public, private and voluntary sectors in prisons and probation. London: Criminal Justice Alliance, 2012. Online article available at http:// www.criminaljusticealliance.org/delivering_justice. pdf (accessed June 2014).

18. World Health Organization. Health in prisons a WHO guide to the essentials in prison health. Denmark: WHO, 2007.

19. Cornford C S, Mason J, Buchanan K et al. A survey of primary and specialised health care provision to prisons in England and Wales. Primary Health Care Research and Development 2008; 9: 126-135.

20. Wang E A, White M C, Jamison R, Goldenson J, Estes $M$, Tulsky J P. Discharge planning and continuity of health care: findings from the San Francisco county Jail. Am J Public Health, 2008; 98: 2182-2184.

21. HM Prison Service, Department of Health, National Offender Management Service (NOMS). Guidance notes: prison health performance and quality indicators. London: DH, 2008.

22. Rose J L, Cleary A. Care staff perceptions of challenging behaviour and fear of assault. J Intellect Dev Disabil 2007; 32: 153-156.

23. NHS primary Care Contracting, Faculty of General Dental Practice (UK), The Royal College of Surgeons of England. Guidelines for the appointment of dentist with special interests (DwSIs) in prison dentistry. London: Royal College of Surgeons of England, 2007. 24. National Association of Prison Dentistry (NAPDUK). 


\section{PRACTICE}

Annual conference. Online details available at http:// www.napduk.org/2014-annual-conference-a-blue-

print-for-the-future/ (accessed June 2014).

25. Heidari E, Dickinson C, Wilson R, Fiske J. Verifiable CPD Paper: oral health of remand prisoners in HMP Brixton, London. Br Dent J 2007: 202: E1.

26. British Society of Disability and Oral Health.
Commissioning tool for special care dentistry. London: $\mathrm{DH}, 2006$.

27. Gallagher J E, Fiske J. Special care dentistry: professional challenge. Brit Dent J 2007; 202: 619-629.

28. Hek G. Unlocking potential: challenges for primary health care researchers in the prison setting.
Primary Health Care Research and Development 2006; 7: 91-94.

29. Gatherer A, Moller L, Hayton P. The World Health Organization European Health in Prison project after 10 years: persistent barriers and achievements. Am J Public Health 2005 95: 1696-1700. 